\section{Rail network must protect giant pandas}

Construction of a high-speed rail network in southwest China is a welcome boost to the region's economy. As the network expands under the country's 13th Five-Year Plan (2016-20), we urge the government to reinforce and extend its efforts to protect the region's giant pandas and prevent further fragmentation of their habitat.

The giant panda (Ailuropoda melanoleuca) is a protected species, so the Chinese government included an expensive system of tunnels and bridges to minimize disruption to its core habitat during the building of the ChengduLanzhou railway, the first part of the network extension that began in 2013. Investment in further safeguards is essential as the network grows. Construction should not pollute groundwater or create deep cuttings and steep embankments; losses of soil, water and vegetation will all need to be remedied. The ends of bridges and tunnels should be kept away from panda areas, which must also remain free of building waste and materials. Providing wildlife corridors will enable the animals to cross the tracks safely.

Environmental protection must not cease after the railway is complete. To minimize noise, light and vibration between dusk and dawn, when pandas are most active, the trains should not run at night.

Shucai Li, Shaoshuai Shi, Lin

Bu Shandong University, Jinan, China.

shishaoshuai@sdu.edu.cn

\section{Boost multinational clinical research}

Global cooperation in clinical research maximizes access to patients, enables resource sharing and increases the applicability of research findings. Yet academic trials are rarely multinational because they are beset with funding problems and variations in legal, regulatory and ethical requirements. The Clinical Research Initiative for Global Health (CRIGH) has taken up the challenge to overcome these.

CRIGH is a worldwide partnership of research institutions and organizations that aims to establish a framework for international cooperation in non-commercial clinical trials and to promote evidence-based medicine (see www.crigh.org). It is a follow-up to the Organisation for Economic Co-operation and Development (OECD) Global Science Forum initiative (see go.nature.com/2prercq). So far, CRIGH has 37 member and observer organizations from 5 continents, including the OECD and the World Health Organization.

The initiative is tackling such issues as infrastructure, funding, ethics, regulatory awareness, and comparative effectiveness and socio-economic impact in multinational clinical research. After just a few months in existence, it is consolidating international research standards, promoting new methodologies and technologies such as data management and sharing, and organizing clinical trials of treatments for rare diseases. Jacques Demotes-Mainard ${ }^{*}$ European Clinical Research Infrastructure Network, Paris, France.

jacques.demotes@ecrin.org ${ }^{\star}$ On behalf of 5 correspondents (see go.nature.com/2qbaqt for full list).

\section{Japan must admit it can't predict quakes}

Japan's government is still failing to protect the public against earthquakes, six years on from the devastating magnitude-9.1 Tohoku earthquake of 2011. In my view, it urgently needs to abandon flawed, old policies and focus instead on implementing effective countermeasures that are based on sound research.

Despite my earlier advice (R. J. Geller Nature 472, 407-409; 2011), the government continues to claim that a magnitude- 9 earthquake is highly likely in the TokaiNankai district during the next 30 years. This claim is based on the false hypothesis that great earthquakes of magnitude 8 or more occur cyclically (see Y. Y. Kagan et al. Seismol. Res. Lett. 83, 951-953; 2012). Clinging to such repudiated models even after the 'unexpected' 2011 Tohoku quake is, in my view, cognitive dissonance on a massive scale.

In my 2011 Comment article, I also advocated repeal of Japan's 1978 Large-Scale Earthquake Countermeasures Act (LECA). LECA is based on the false premise that precursors of a great earthquake in the Tokai district can be detected accurately enough for a legally binding three-day state of emergency to be declared. However, the act is still in place. The government intends to tweak it to cover a larger land area, while authorizing the issuance of warnings that fall short of a state of emergency (see 'Don't rely on quake predictions', The Japan Times 7 July 2016).

I urge the government to explicitly inform the public that prediction of imminent earthquakes is currently impossible. It should repeal LECA and adopt earthquake countermeasures that are based on sound science.

Robert J. Geller University of Tokyo, Japan.

bob@eps.s.u-tokyo.ac.jp

\section{Widen discipline span of Nature papers}

Our informal analysis indicates that the biological sciences have dominated Nature's research content for more than 50 years. In an age that calls for greater multidisciplinarity, we suggest that the journal should include a broader range of high-impact papers from fields such as mathematics, chemistry and applied science.

We searched Clarivate Analytics' Web of Science database for Nature papers published in several different research fields during 1963-64, 2003-04 and 2013-14. We estimate that biological sciences account for $53 \%$ of Nature's content, averaged over all three periods $(55 \%, 48 \%$ and $56 \%$, respectively). By contrast, mathematics contributed 5\%, chemistry $11 \%$ and applied sciences $10 \%$, on average (details available from authors on request). These numbers are necessarily approximate because, for example, a paper may fall into more than one research category and definitions of applied science can be subjective.

Over the period we analysed, molecular biology and the biomedical sciences have seen vast progress. Together with the high number of citations those fields collect, this could explain the journal's seeming preference for articles in these areas. However, relatively few articles contribute to a journal's high impact factor (see V. Larivière et al. Preprint at bioRxiv http:// dx.doi.org/10.1101/062109; 2016). We therefore recommend sacrificing some candidate life-sciences papers for contributions with high citation potential from underrepresented areas. Gabriel José de Carli, Tiago Campos Pereira University of São Paulo, Brazil. tiagocampospereira@ffclrp.usp.br

\section{CORRECTION}

The Correspondence by Tim Birkhead and Robert Montgomerie (Nature 545, 30; 2017) wrongly stated that PeerJ is a not-for-profit journal. In fact, it is a for-profit company. 